\title{
ALKOHOLISMUS
}

\section{Abstinenz: Neuer Mumm für die Knochen}

Alkoholkranke, die von der Flasche lassen, dürfen mit einer raschen Zunahme ihrer Knochendichte rechnen. Forscher der Universität Innsbruck haben untersucht, wie sich Marker des Knochenauf- und -abbaus bei alkoholkranken Patienten vor und während der Abstinenz entwickeln. Zu Beginn der Studie war der Knochenstoffwechsel deutlich in Richtung Abbau verschoben. Das änderte sich mit der Abstinenz, und zwar bereits binnen zweier Monate: Die
Osteocalcin-Werte stiegen signifikant, im Durchschnitt von 21,5 $\mu \mathrm{g} / \mathrm{l}$ auf 25,5 $\mu \mathrm{g} / \mathrm{l}$ (Norm: 15-35 $\mu \mathrm{g} / \mathrm{l}$ ). Das Ungleichgewicht zwischen Auf- und Abbau von Knochenmasse tendierte zur Balance. Als besonderer Schutzfaktor habe sich körperliche Aktivität erwiesen. Sportliches Training sei deshalb ein sinnvoller Bestandteil der Therapie von Alkoholkranken.

Alcohol Clin Exp Res 2012, doi: 10.1111/j.15300277.2012.01834.x

\section{EMOTIONALE VERNACHLÄSSIGUNG}

\section{Als Kind traumatisiert - im Alter Schlaganfall?}

Die Folgen psychischer Traumata durch emotionale Vernachlässigung in der Kindheit reichen möglicherweise bis ins höhere Alter: Das Schlaganfallrisiko scheint bei den Betroffenen erhöht zu sein.

Neurologen vom Rush Alzheimer's Disease Center in Brooklyn/New York befragten ca.1000 Studienteilnehmer im Alter über 55 Jahren zu Vernachlässigungen und Misshandlungen in ihrer Kindheit. Im Studien- zeitraum von dreieinhalb Jahren starben 192 Teilnehmer, bei denen schließlich eine Autopsie des Gehirns vorgenommen wurde. Die statistische Auswertung ergab eine Assoziation zur emotionalen Vernachlässigung. Bei starker Vernachlässigung war das Schlaganfallrisiko im Vergleich zu Studienteilnehmern mit geringerer Vernachlässigung um das 2,8-Fache erhöht.

Neurology 2012;79:1524-1525

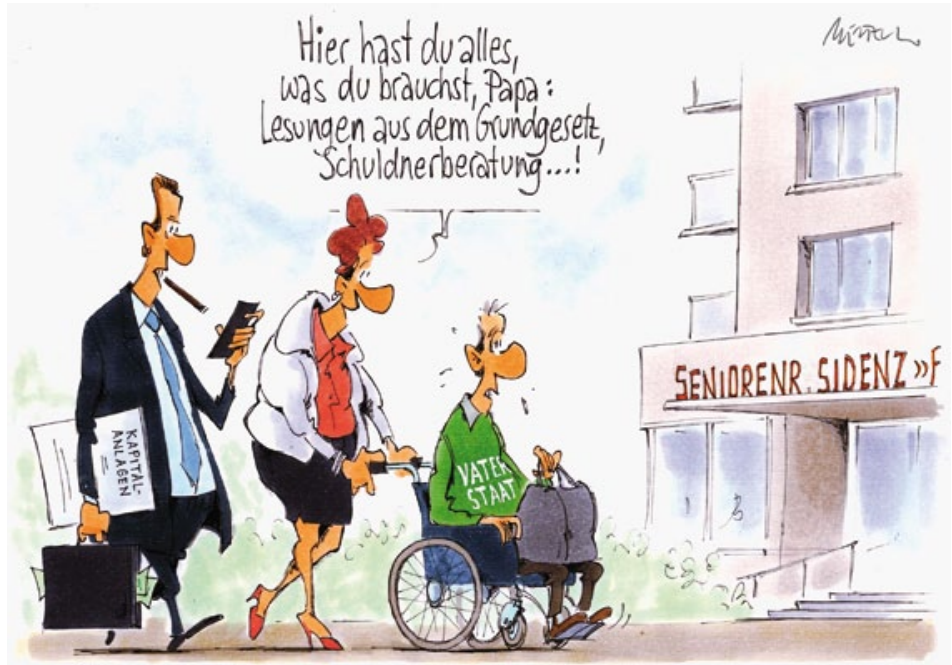

Vater Staat als Pflegefall? Um echte geriatrische Patienten geht es ab S. 46.
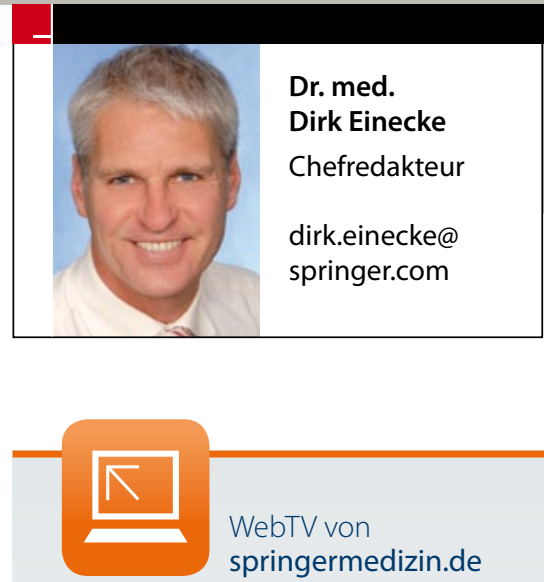

Kinder- und Jugendmedizin im Fokus

Auf der Jahrestagung der Kinderund Jugendmedizin sprach springermedizin.de u. a. mit dem Impfexperten Prof. Markus Knuf über sinnvolle und überflüssige Impfungen und mit Sozialisations- und Bildungsforscher Prof. Klaus Hurrelmann über Segen und Fluch von Internet \& Co. Alle Videos finden Sie unter www. springermedizin.de/webtv

\section{ADIPOSITAS}

\section{Schlaflos und dick}

Es gibt einen Zusammenhang zwischen chronischem Schlafmangel und der Adipositas. Schlafdefizit verändert einige Komponenten, die üblicherweise den Appetit kontrollieren: So sinkt der Leptinspiegel, während Ghrelin und Kortisol ansteigen. Untersuchungen an übergewichtigen Erwachsenen, die 14 Tage unter eine moderate Diät gesetzt wurden, haben gezeigt, welchen Vorteil ausreichender Schlaf hat Zwar verloren beide Gruppen im Schnitt 3 kg an Körpergewicht. Doch bei denjenigen, die 8,5 Stunden schliefen, waren 55\% davon Fett, während sich Nachtaktive mit nur 5,5 Stunden Schlaf mit der gleichen Diät nur eines Anteils von 25\% Fett entledigen konnten.

CMAJ 2012; online 17. September. DOI:10.1503/ cmaj. 120876 